\title{
Modeling of Interstitial Microwave Hyperthermia for Hepatic Tumors Using Floating Sleeve Antenna
}

Faihaa Eltigani

University of Gezira

Sulafa Ahmed ( $\nabla$ sulafa174@gmail.com )

University of Gezira https://orcid.org/0000-0003-2237-8891

Maged Yahya

University of Gezira

Mawahib Ahmed

University of Gezira

Research

Keywords: Liver tumor, Microwave hyperthermia, Sleeve antenna, Pennes' equation, metabolic rate.

Posted Date: September 22nd, 2021

DOI: https://doi.org/10.21203/rs.3.rs-900511/v1

License: (c) (1) This work is licensed under a Creative Commons Attribution 4.0 International License.

Read Full License 


\section{Abstract}

Background: Liver tumor, also known as hepatic tumor is one of the most common cancers with $80 \%$ of cases occurs in developing countries. Microwave hyperthermia is one of the promising treatment modalities that use microwaves to destroy the cancer cells by rising their temperature to $41-45^{\circ} \mathrm{C}$. This temperature elevation is achieved by using an applicator such as antennas. This study aims to design a microwave sleeve antenna capable of heating hepatic tumors (with different sizes and locations) to the therapeutic range of temperature for hyperthermia.

Method: The sleeve antenna was designed to be resonate at $2.45 \mathrm{GHz}$ and tested in a free space. Then; the antenna was tested in 6 different 3D liver models: Model A: without a tumor or blood vessels, Model $\mathrm{B}$ : with a tumor $(2 \mathrm{~B} 3 \mathrm{~cm})$ and without blood vessels, Model $\mathrm{C}$ : created by adding blood vessels to model $\mathrm{B}$, then a small tumor $(1.5 \mathrm{a} 1.5 \mathrm{~cm})$ was created and its location (Model D) and size (Model E) were changed. Finally, a model with a spherical tumor of $1.5 \mathrm{~cm}$ diameter (Model F) was tested.

Results: The return loss (S-parameters) of the antenna was varied from $-45 \mathrm{~dB}$ to $-25 \mathrm{~dB}$ in the different liver models. The Specific Absorption Rate (SAR) reached $30 \mathrm{~W} / \mathrm{kg}$ in the tumor and less than $24 \mathrm{~W} / \mathrm{kg}$ in the surrounding tissues, while the tumor temperature elevated to the therapeutic ranges of hyperthermia in the all models and the surrounding tissues remain at a safe temperature range.

Conclusions: The obtained results showed the capability of the designed antenna to raise the temperature of hepatic tumors to the therapeutic ranges of hyperthermia.

\section{Background}

The incidence rate for liver (Hepatic) cancer has more than tripled since 1980 in United States with estimated 42,230 new cases in 2021 and about 30,230 are expected to die of these cancers [1]. Liver cancer is about 3 times more common in men than in women and it is primary liver cancer (originated in the liver) or metastatic liver cancer (spread from cancer sites elsewhere in the body) [1]. The most common form in adults is called Hepatocellular Carcinoma (HCC) [2].

Currently, surgical resection is considered as a standard option for the treatment of liver cancer since it has been shown to provide survival benefits, moreover, chemotherapy and radiotherapy are not well accepted from the patients due to their side effects [2]. Owing to a variety of reasons such as multifocal disease, tumor size, the presence of many tumors, and tumor location in relation to key blood vessels; only $5-15 \%$ of HCC patients and other hepatic metastasis could undergo such curative surgery [2]. Nowadays, there is a emergent need for interstitial techniques for the treatment of hepatic tumors by hyperthermia, in which, an applicator is inserted inside the liver to elevate it is temperature [3]. The basic idea of hyperthermia treatment is to rise a temperature of the tumor to $41-45^{\circ} \mathrm{C}$ without damaging the surrounding normal tissues [4]. According to Barcelona Clinic Liver Cancer system, hyperthermia is considered as a standard of care for unresectable HCC in very early stages of the disease [5]. 
Microwave hyperthermia is considered as one of the most promising hyperthermia techniques. It has been applied to thousands of patients suffering from prostate, breast and liver cancer. In this technique, microwave-generated heat is used to shrink or destroy cancerous tumors [2].

The basic devices to perform an interstitial Microwave hyperthermia consist of microwave generator, microwave applicator (the antenna), and a flexible coaxial cable to connect the antenna to the microwave generator [4]. Using these Microwave hyperthermia devices has many advantages such as the ability of designing a very thin antenna (avoid damaging of surrounding tissues), low-risk procedures and can be repeated in another session of therapy when new lesions appear [6].

Many studies designed microwave sleeve antennas for hepatic hyperthermia using simple models of both tumors and liver [6-11]. Using of simple models could not reflect the actual process as when using a realistic 3D model. In addition, majority of the previous studies calculated the Specific Absorption Rate (SAR) which is not sufficient indicator of raising the tumor temperature to the hyperthermia therapeutic range.

The objective of this work is to design a microwave sleeve antenna capable of heating the hepatic tumors to the therapeutic range of temperature for hyperthermia using realistic 3D liver and tumor models.

\section{Results}

Various simulations were carried out at $2.45 \mathrm{GHz}$ to test the proposed antenna. The antenna showed the capability of rising the temperature of hepatic tumors to above $41^{\circ} \mathrm{C}$. On the other hand, the temperature of the surrounding tissues was remained below $41^{\circ} \mathrm{C}$. For each simulation model, the S-parameters (Return loss), SAR and temperature were calculated.

\section{S-parameters Results}

Values of the S-parameters at $2.45 \mathrm{GHz}$ were varied from $-45 \mathrm{~dB}$ to $-27 \mathrm{~dB}$ (Fig. 1). This variation is due to the changing of the tumor size and location. It could be observed that the maximum value $(-45 \mathrm{~dB})$ was obtained in model $\mathrm{F}$ (spherical tumor) and the minimum value $(-27 \mathrm{~dB})$ was obtained in the model $\mathrm{A}$ (model without tumor and blood vessels).

\section{Sar Results}

The liver models were varied from a very simple model to a complex model. The SAR value for model A (without tumor and blood vessels) was $30.2 \mathrm{~W} / \mathrm{Kg}$ (Fig. 2.a). The SAR values were varied from $31.4 \mathrm{~W} / \mathrm{Kg}$ to $29.4 \mathrm{~W} / \mathrm{Kg}$ for the others models with tumors (Figs. 2.b-e). In these models, the high SAR value was observed in model B (without blood vessels) (Fig. 2.b). The spherical tumor (Fig. 2.f) showed a semi uniform distribution of SAR in the whole tumor. 


\section{Temperature Results}

Considering that the SAR values alone are not sufficient to access the hyperthermia process, it is important to calculate the temperature of the tumor and surrounding tissues by substituting the SAR values into the Pennes' bioheat equation. Figure 3 shows the temperature pattern in all six models. It could be observed that the in model A (Fig. 3.a) where there is no tumor, the higher obtained temperature was 39.7 which is still below the hyperthermia range. For the other models, the temperature elevation in the tumors is within the hyperthermia therapeutic range $\left(41-45^{\circ} \mathrm{C}\right)$. Compared to the other models with realistic tumors (Figs. 3b-e), the temperature pattern in the model with the spherical tumor (Fig. 3.f) shows a uniform distribution. Model C (Fig. 3.C) showed the best results with temperature reached 45.6 ${ }^{\circ} \mathrm{C}$ with a good distribution along the tumor. The spherical tumor (Fig. 3.f) showed a uniform distribution of temperature in the whole tumor.

\section{Discussion}

In this study, a new design of a sleeve antenna for microwave hyperthermia was introduced. The antenna was testing in six different liver models then the S-parameters, SAR and temperature were measured.

The results showed that the S-parameters values at $2.45 \mathrm{GHz}$ (Fig. 1) are varying when changing the tumor size and location. Comparing the obtained S-parameters values $(-45 \mathrm{~dB}$ to $-27 \mathrm{~dB})$ with other two studies used to design of the proposed antenna, it could be observed that current study has a smaller Sparameters values.

The study of Maini obtained a return loss of $-24.8 \mathrm{~dB}$ at $2.45 \mathrm{GHz}$, while, Chaichanyut and Tungjitkusolmun obtained a return loss of $-20 \mathrm{~dB}$ at $2.45 \mathrm{GHz}$ ([6] and [12]). Since efficiency of an antenna is mainly dependent on the antenna's S-parameters which is the ratio of reflected power to input power. Smaller S-parameters indicates greater output power coupled to tumor.

The used 3D liver models were varied from a very simple model (without tumor and blood vessels) to a complex model. For the models with tumors, high SAR values were observed in the tumor placed at a model without blood vessels (Fig. 2.a). This could be interpreted by the absence of the blood vessels (high conductivity) which affect the SAR value. In the other complex models, it could be observed the focusing of high SAR within the tumor (Figs. 2.b-d). This result could be interpreted by the good localization of the designed antenna and the high conductivity of the tumor.

Considering that shape, volume, and surface area affect the amount of absorbed microwaves and subsequently energy focusing and overheating [13], we could observed that SAR pattern in the model with the spherical tumor shows a uniform distributions and lower SAR values compared to the realistic tumors (Fig. 2.e). This observation highlights the significance of using a 3D realistic liver model to assess the effectiveness of any microwave antenna design to be used for hyperthermia. The majority of the previous studies such as $[6,8-10]$ used simple models to test the performance of their applicators. 
This may lead to good results but not with the same accuracy obtained by using realistic models. In addition, using realistic models will help in the 3D planning for the clinical application of hepatic tumor hyperthermia.

One of the main parameters in the bioheat equation is the metabolic rate. It represents the mechanism for modeling physiological heat generation. Based on the results obtained from a model without a tumor (Fig. 3.a), it is clear that metabolic rate plays a fundamental role in rising tumor temperature since the temperature is uniform in the whole model with slight increase $\left(1^{\circ} \mathrm{C}\right)$ around the tip of the antenna. Taking into account the assumptions mentioned above about the increase of tumor temperature about 0.5 to $3^{\circ} \mathrm{C}$, the antenna performs heating to about $6^{\circ} \mathrm{C}$. Moreover, the presence of blood vessels shows direct effect on temperature distribution (Fig. 3. a,b), since the temperature decreased in the upper side of the tumor in the figure which is the part of tumor close to the lateral blood vessel.

Sajan Singh et al [14] designed a coaxial antenna for microwave hyperthermia and tested its performance in a realistic liver model (without blood vessels). In compare to the proposed antenna, they obtained the required temperature for microwave hyperthermia after applying a power of up to $4 \mathrm{~W}$ with longer simulation time (up to 30mins) which reflected the potentiality of using floating sleeve antenna for interstitial microwave hyperthermia applications.

The most important point to be noted that most of the related works such as [11] neglected the metabolic rate in the bioheat equation despite it is main rule in the heat generation process. It is also noted that some studies depend mainly on SAR patterns in evaluating the efficiency of the designed applicator such as study of [15], but SAR does not describe the temperature values and distribution, since they depend on other parameters such as blood flow and metabolic rate for tumor and surrounding tissues.

In the future work, authors will consider the enhancing the antenna design to be smaller. In addition, the antenna should be tested in a 3D model with more than one tumor located in different locations.

\section{Conclusion}

This study aims to design an interstitial microwave antenna capable of heating hepatic tumors. The designed antenna was tested in 6 liver models. The irradiating antenna was inserted into each liver model. The study shows the feasibility the proposed sleeve antenna in raising the temperature of hepatic tumors to the therapeutic values using simple, inexpensive and easy to fabricate components. It is to be concluded that the designed antenna worked properly with tumors with sizes of around $2 \times 3 \mathrm{~cm}$. while tumors with larger size can be ablated with more than one hyperthermia session with different insertion sites.

\section{Method}

Antenna design and it is interactions with the liver tissues were simulated with Computer Simulation Technology (CST) software. CST [16] is a powerful simulation platform for electromagnetic problems. It 
provides multiple simulation modules, two of them were used in this work; the CST MICROWAVE STUDO and the CST MPHYSICS STUDO. The first one was used to calculate the antenna parameters and the specific absorption rate (SAR) in the liver and tumor, while the second module was used to calculate the temperature elevation due to the absorption of electromagnetic energy.

\section{A. Antenna Design}

The antenna was designed from a $50 \Omega$ coaxial cable, with copper inner and outer conductors separated by Polytetrafluoroethylene (commonly known by its trade name, Teflon) as a dielectric material. The antenna is a $3.4 \mathrm{~mm}$ in diameter with Teflon to act as a catheter. The antenna also covered by Teflon tape for easy insertion and removal after hyperthermia. Antenna geometry parameters, slot spacing, and floating sleeve length were chosen based on the effective wavelength in human liver tissue at $2.45 \mathrm{GHz}$, which calculated using the Eq. 1 [8]:

$$
\lambda_{\text {eff }}=\frac{\mathrm{c}}{\mathrm{f} \sqrt{\epsilon_{\mathrm{r}}}}
$$

1

Where $\mathrm{c}$ is the speed of light in free space measured in $(\mathrm{m} / \mathrm{s}), \mathrm{f}$ is the operating frequency of the microwave generator $(2.45 \mathrm{GHz})$, and $\epsilon_{\mathrm{r}}=43.03$ is the relative permittivity of human liver tissue at the operating frequency; this yielded the effective wavelength of approximately $18.667 \mathrm{~mm}$. The equation only provides a very crude approximation for the design. Generally, slot spacing, floating sleeve length corresponds to $0.25 \lambda_{\text {eff }}$, and $\lambda_{\text {eff }}$ respectively, which are chosen and then optimized to achieve localized power deposition near the distal tip of the antenna. Figure 4 shows the schematic diagram of the designed floating sleeve antenna (dimensions in $\mathrm{mm}$ ). The diameters of each layer are illustrated in Table 1.

Table.1. Dimensions of the designed antenna 


\begin{tabular}{|ll|}
\hline Dimension & Value (mm) \\
\hline Diameter of the inner conductor & 0.5 \\
\hline Outer Diameter of the dielectric material & 1.6260 \\
\hline Outer diameter of outer conductor & 1.7886 \\
\hline Inner diameter of the sleeve & 2.5 \\
\hline Outer diameter of the sleeve & 3.2 \\
\hline Diameter of the inner tip & 2.6 \\
\hline Diameter of the outer tip & 3.4 \\
\hline
\end{tabular}

In the antenna design, the pattern of a linear dipole with an overall length less than the half-wavelength $(L<\lambda / 2)$ is insensitive to the frequency [17]. Thus, the length is chosen to be greater than the halfwavelength. The equation that used to calculate the wavelength is:

$$
\lambda=\frac{\mathrm{c}}{\mathrm{f}}
$$

2

Where $\mathrm{c}$ is the speed of light in free space and $\mathrm{f}$ is the operating frequency of the microwave generator $(2.45 \mathrm{GHz})$, this result in half-wavelength of $61.18 \mathrm{~mm}$.

\section{A. The Original Liver Model}

A realistic 3D liver model was downloaded from 3D-IRCADb-01 database [18], which composed of 3D Computed Tomography (CT) scans of 10 women and 10 men with hepatic tumors. In this study, a man liver with blood vessels and a tumor $(2 \times 3 \mathrm{~cm})$ was used. This model was used to generate 6 different models as will be explained later.

\section{B. Assigning Material Properties}

The electrical properties (dielectric constant and conductivity) and the thermal properties for different liver tissues were assigned according to the literature [19] [8, 9, 12, 20-27], and the CST material library. All dielectric properties were chosen at the operating frequency $(2.45 \mathrm{GHz})$.

The assigning of metabolic properties was one of the main challenges in this work, since up to our knowledge; there are no any reported values for the metabolic rate of hepatic tumors. The literature cites the changing of tumors metabolic activities in comparison to the normal cells, and these changes support the acquisition and maintenance of malignant properties [28]. Gorbach et al. used the infrared camera to obtain thermal images of brain tumors, the obtained temperature distribution showed that glial origins of brain tumors have 0.5 to $2{ }^{\circ} \mathrm{C}$ temperature difference compared to surrounding brain tissues 
which is due to high metabolic processes [29]. In addition, a study of Mital et al. discussed that local temperatures of the skin over a tumor were significantly higher (about 2-3 degrees) than normal skin temperatures. This was due to convection effects associated with increased metabolism around the tumor [21].

In compare to breast and brain, liver has a higher metabolic rate [30]. Based on this, the basal metabolic rate in tumor was chosen to be 10 times of the surrounding tissues $(120000 \mathrm{~W} / \mathrm{m} 3)$, with $3400 \mathrm{~W} / \mathrm{m}^{3} / \mathrm{K}$ as perfusion rate. Table 2 presents the assigned material properties.

Table 2

Material properties used Bio-heat equation (at $2.45 \mathrm{GHz}$ )

\begin{tabular}{|llll|}
\hline Property & Liver & Blood & Tumor \\
\hline Relative permittivity $\left(\mathbb{\nabla}_{\mathrm{r}}\right)$ & 43.03 & 58.30 & 48.16 \\
\hline Electrical conductivity $(\sigma)$ & 1.69 & 2.54 & 2.09 \\
\hline Density $(\rho)$ & 1060 & 1000 & 1045 \\
\hline Specific heat capacity $\left(c^{b}\right)$ & 3600 & 4180 & 4200 \\
\hline Thermal conductivity $(k)$ & 0.512 & 0.49 & 0.60 \\
\hline Blood flow coefficient & 68000 & $1 \mathrm{e}+006$ & 3400 \\
\hline Basal metabolic rate BMR & 12000 & - & 120000 \\
\hline
\end{tabular}

Increasing of biological tissues temperature depends on the spatial distribution of the electromagnetic fields, the governing thermodynamics, and the thermal constitutive parameters of the biological system. The thermal energy calculations in this study were based on Pennes' suggestion, expressed in the following equation:

$$
\rho \mathrm{c} \frac{\partial \mathrm{T}}{\partial \mathrm{t}}=\mathrm{k} \frac{\partial^{2} \mathrm{~T}}{\partial \mathrm{x}^{2}}+\mathrm{k} \frac{\partial^{2} \mathrm{~T}}{\partial \mathrm{y}^{2}}+\mathrm{k} \frac{\partial^{2} \mathrm{~T}}{\partial \mathrm{z}^{2}}+\mathrm{w}_{\mathrm{b}} \mathrm{c}_{\mathrm{b}}\left(\mathrm{T}_{\mathrm{a}}-\mathrm{T}\right)+\mathrm{Q}_{\mathrm{m}}+\mathrm{Q}_{\mathrm{r}}(\mathrm{x}, \mathrm{y}, \mathrm{z}, \mathrm{t})
$$

3

Where $\mathrm{T}=\mathrm{T}(\mathrm{x}, \mathrm{y}, \mathrm{z}, \mathrm{t})$ is the temperature elevation $\left({ }^{\circ} \mathrm{C}\right), \mathrm{\rho}$ the physical density of the tissue $\left(\mathrm{kg} / \mathrm{m}^{3}\right)$, $\mathrm{c}$ the specific heat of the tissue $\left(\mathrm{J} / \mathrm{kg} /{ }^{\circ} \mathrm{C}\right), \mathrm{k}$ the tissue thermal conductivity $\left(\mathrm{W} / \mathrm{m}^{\circ} \mathrm{C}\right), \mathrm{w}_{\mathrm{b}}$ the blood volumetric perfusion rate $\left(\mathrm{kg} / \mathrm{m}^{3} / \mathrm{s}\right), \mathrm{c}_{\mathrm{b}}$ the specific heat of blood $\left(\mathrm{J} / \mathrm{kg} /{ }^{\circ} \mathrm{C}\right)$, and $\mathrm{T}_{\mathrm{a}}=\mathrm{T}_{\mathrm{a}}(\mathrm{x}, \mathrm{y}, \mathrm{z}, \mathrm{t})$ the average temperature elevation of the arteries $\left({ }^{\circ} \mathrm{C}\right) . \mathrm{Q}_{\mathrm{m}}$ is the mechanism for modeling physiological heat generation $\left(\mathrm{W} / \mathrm{m}^{3}\right)$ and $\mathrm{Q}_{\mathrm{r}}$ the regional heat delivered by the source $\left(\mathrm{W} / \mathrm{m}^{3}\right)$. The term $\mathrm{w}_{\mathrm{b}} \mathrm{c}_{\mathrm{b}}\left(\mathrm{T}_{\mathrm{a}}-\mathrm{T}\right)$, which is the perfusion heat loss $\left(\mathrm{W} / \mathrm{m}^{3}\right)$, is always considered in the case of tissues which have a high degree of perfusion, such as a liver. In general, $\mathrm{w}_{\mathrm{b}}$ is assumed to be uniform throughout the tissue. However, its value may increase with heating time because of vasodilation and capillary recruitment [2]. 


\section{The Whole System (Antenna And Liver) Simulation}

The simulation started in CST MICROWAVE STUDO, where the antenna was designed. Then, the liver model was imported and materials properties were assigned. The transient solver of CST MICROWAVE STUDO was used to calculate the antenna parameters and the Specific Absorption Rate (SAR). The thermal solver in CST MPHYSICS STUDIO was used to solve the Pennes' bioheat equation taking into account the effects of living tissue such as metabolic mechanisms and blood flow influence.

The initial temperature of $25^{\circ} \mathrm{C}$ and $37^{\circ} \mathrm{C}$ for the surrounding ambient and tissues respectively was set. While, open boundary conditions were set for both solvers. The results were taken with 10 minutes simulation time.

Figure 5 shows the whole system with different models. The designed antenna was tested firstly in a liver model without a tumor or blood vessels (Model A), then in a model with a tumor of about $2 \times 3 \mathrm{~cm}$ and without any blood vessels (Model B). After that, the antenna is tested in a complete model with the same tumor and blood vessels (Model $\mathrm{C}$ ). To test the effect of both size and location of the tumor, the location of the original tumor was changed (Model $D)$ and the tumor was shrieked to $(1.5 \times 1.5 \mathrm{~cm})($ Model $\mathrm{E})$. Finally, a model with a spherical tumor of $1.5 \mathrm{~cm}$ diameter (Model F) was tested. An ElectromagneticThermal coupling platform was initiated and in each time, SAR and temperature distributions were recorded.

\section{Abbreviations}

HCC Hepatocellular Carcinoma

SAR Specific Absorption Rate

\section{Declarations}

\section{Ethics approval and consent to participate}

Not applicable.

\section{Consent for publication}

The participants acknowledged their consent to publish the acquired data.

\section{Availability of data and materials}

The datasets used and/or analyzed during the current study are available from the corresponding author on reasonable request. 


\section{Competing interests}

The authors declare that they have no competing interests.

\section{Funding}

This research did not receive any specific grant from funding agencies in the public, commercial, or notfor-profit sectors.

\section{Authors' contributions}

Faihaa Eltigani and Sulafa Ahmed carried out the concept and design of the study and interpreted the data. Mawahib Ahmed and Maged Yahya provided critical revision of the manuscript for important intellectual content. All authors read and approved the final manuscript.

\section{Acknowledgements}

Not applicable.

\section{Author details}

${ }^{1}$ Electronics Engineering Department/ Faculty of Engineering and Technology, University of Gezira, Main Camp, El-nishaishipa, Po. Box: 20,Wad Madni , Sudan.

\section{References}

1. American Cancer Society. Key Statistics About Liver Cancer. Available from: https://www.cancer.org/cancer/liver-cancer/about/what-is-key-statistics.html. Accessed 08 September 2021.

2. Habash R. Bioeffects and therapeutic applications of electromagnetic energy. 2007 Nov 19: CRC press.

3. Potretzke TA, et al. Microwave versus radiofrequency ablation treatment for hepatocellular carcinoma: a comparison of efficacy at a single center. J Vasc Interv Radiol. 2016;27(5):631-8.

4. Anupma M, et al. Microwave Interstitial Tumor Ablation: New Modality for Treatment of Liver Cancer. depression. 2009;2:3.

5. Facciorusso A, Serviddio G, Muscatiello N. Local ablative treatments for hepatocellular carcinoma: an updated review. World journal of gastrointestinal pharmacology therapeutics. 2016;7(4):477.

6. Maini S. Design optimization of tapered cap floating sleeve antenna for interstitial microwave ablation for liver tumor. in 2016 IEEE International Conference on Consumer Electronics (ICCE). 2016. IEEE.

7. Gas P, Transient Analysis of Interstitial Microwave Hyperthermia Using Multi-Slot Coaxial Antenna, in Analysis and Simulation of Electrical and Computer Systems2015, Springer. p. 63-71. 
8. Rattanadecho P, Keangin P. Numerical study of heat transfer and blood flow in two-layered porous liver tissue during microwave ablation process using single and double slot antenna. Int $\mathrm{J}$ Heat Mass Transf. 2013;58(1-2):457-70.

9. Lara JE, et al. Modeling of electromagnetic and temperature distributions of an intersticial coaxialbased choked antenna for hepatic tumor microwave ablation. in 2015 12th International Conference on Electrical Engineering, Computing Science and Automatic Control (CCE). 2015. IEEE.

10. Islam MM, Islam MA. Radio Frequency Ablation of Liver Tumor-Influence of Vein Wall and Location of Large Vessels. Journal of Biomedical Engineering Medical Imaging. 2017;4(6):23-3.

11. Cepeda Rubio MFJ, et al., Coaxial slot antenna design for microwave hyperthermia using finitedifference time-domain and finite element method. The Open Nanomedicine Journal, 2011. 3(1).

12. Chaichanyut $M$, Tungjitkusolmun $S$. Microwave ablation using four-tine antenna: effects of blood flow velocity, vessel location, and total displacement on porous hepatic cancer tissue. Computational and mathematical methods in medicine; 2016.

13. Yacoob SM, Hassan NS. FDTD analysis of a noninvasive hyperthermia system for brain tumors. Biomedical engineering online. 2012;11(1):1-22.

14. Singh S, Sehgal S, Gill H. FEM anlaysis of microwave hyperthermia and the effect of SAR \&temperature elevation on liver tumor. International Journal of Mechanical Production Engineering Research Development. 2017;3(4):183-97.

15. Nizam-Uddin N, Elshafiey I. Enhanced energy localization in hyperthermia treatment based on hybrid electromagnetic and ultrasonic system: proof of concept with numerical simulations. BioMed research international; 2017.

16. CST CST. CST STUDIO SUITE, 2017, CST Computer Simulation Technology AG: Germany.

17. Balanis CA. Modern antenna handbook. John Wiley \& Sons; 2008.

18. 3D-IRCADb-01. database. . Accessed 12 September 2021.

19. Gabriel S, Lau R, Gabriel C. The dielectric properties of biological tissues: III. Parametric models for the dielectric spectrum of tissues. Phys Med Biol. 1996;41(11):2271.

20. Maini S, Marwaha A. Microwave Interstitial Thermal Ablation of Hepatic Tumors by Extended Tip Sliding Choke Antenna. in 2011 Fourth International Conference on Emerging Trends in Engineering \& Technology. 2011. IEEE.

21. Mital M, Pidaparti RM. Breast tumor simulation and parameters estimation using evolutionary algorithms. Modelling and simulation in engineering; 2008.

22. Keangin $P$, Vafai K, Rattanadecho P. Electromagnetic field effects on biological materials. Int J Heat Mass Transf. 2013;65:389-99.

23. Tungjitkusolmun $S$, et al. Three-dimensional finite-element analyses for radio-frequency hepatic tumor ablation. IEEE transactions on biomedical engineering. 2002;49(1):3-9.

24. Paul A, Pla A, Weng LL. Thermal Modeling of Microwave Percutaneous Hepatic Tumor Ablation.. 
25. Singh S, Repaka R. Pre-clinical modelling and simulation of hepatic radiofrequency ablation. in Proc COMSOL Conference 2015. 2015.

26. Fang Z, et al., Design of a novel electrode of radiofrequency ablation for large tumors: a finite element study. Journal of Engineering and Science in Medical Diagnostics and Therapy, 2018. 1(1).

27. Zhang B, et al. Numerical analysis of the relationship between the area of target tissue necrosis and the size of target tissue in liver tumours with pulsed radiofrequency ablation. Int $\mathrm{J}$ Hyperth. 2015;31(7):715-25.

28. DeBerardinis RJ, Chandel NS. Fundamentals of cancer metabolism. Sci Adv. 2016;2(5):e1600200.

29. Gorbach AM, et al. Intraoperative infrared functional imaging of human brain. Ann Neurol. 2003;54(3):297-309.

30. Marieb EN, Hoehn K. Human anatomy \& physiology. Ninth Edition ed2013: Pearson education.

\section{Figures}

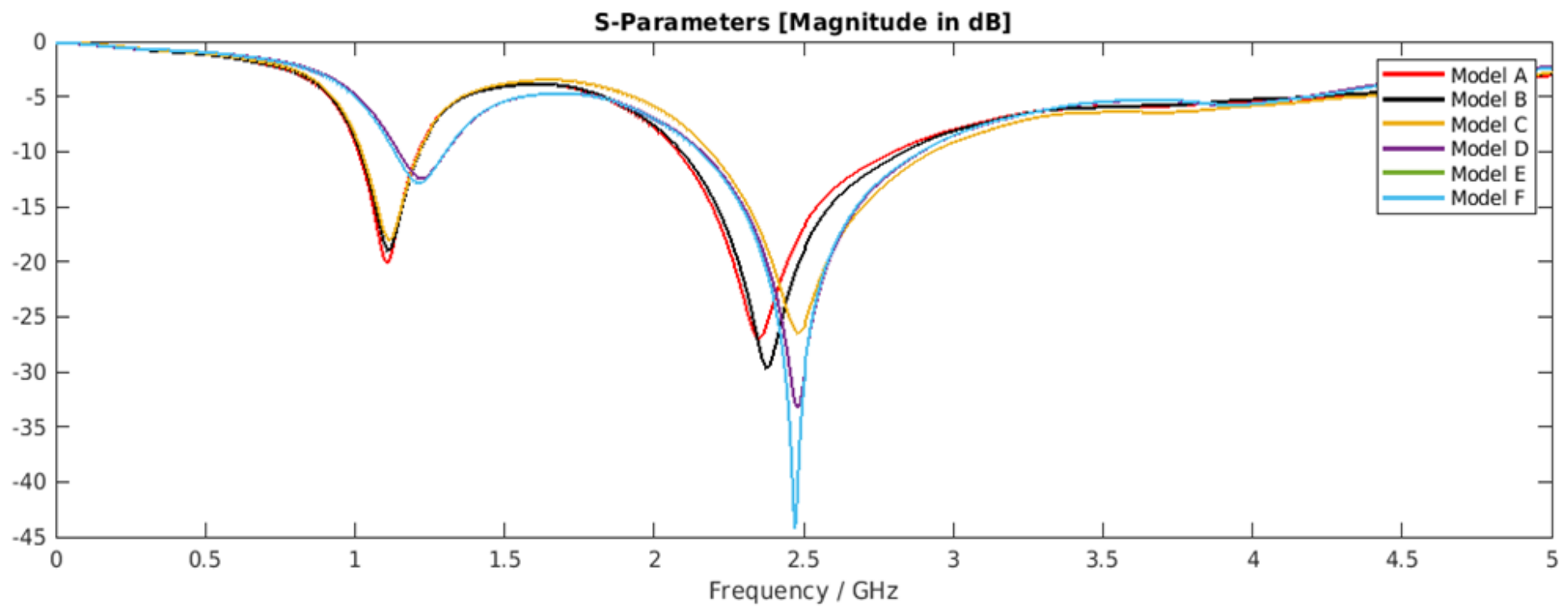

Figure 1

Return loss for antenna with different simulation models 
(a)
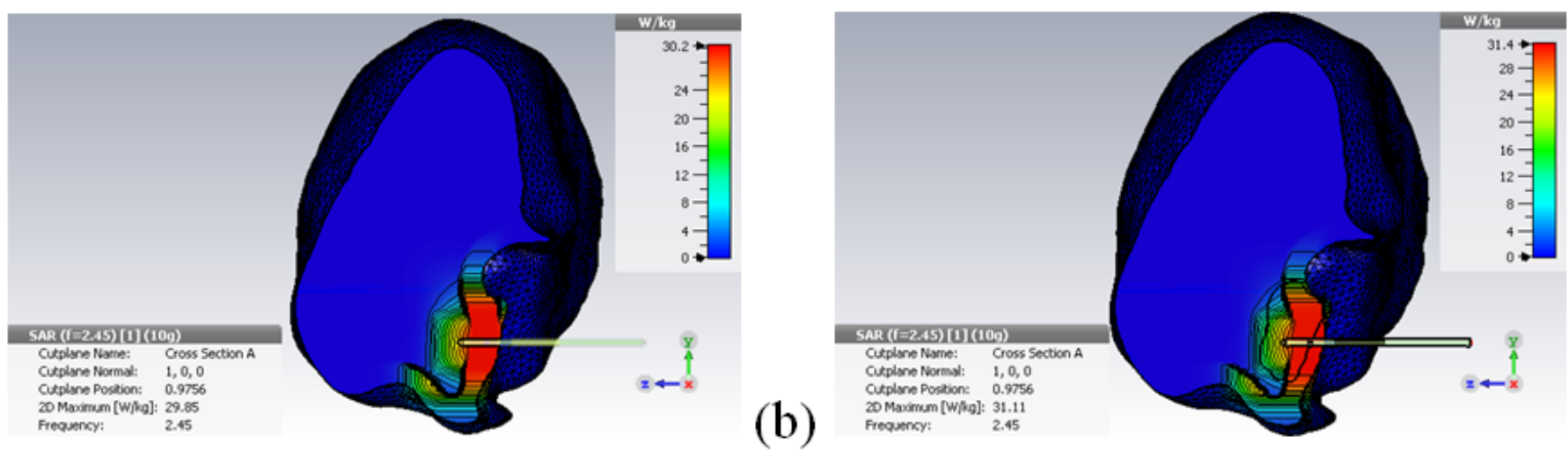

(c)

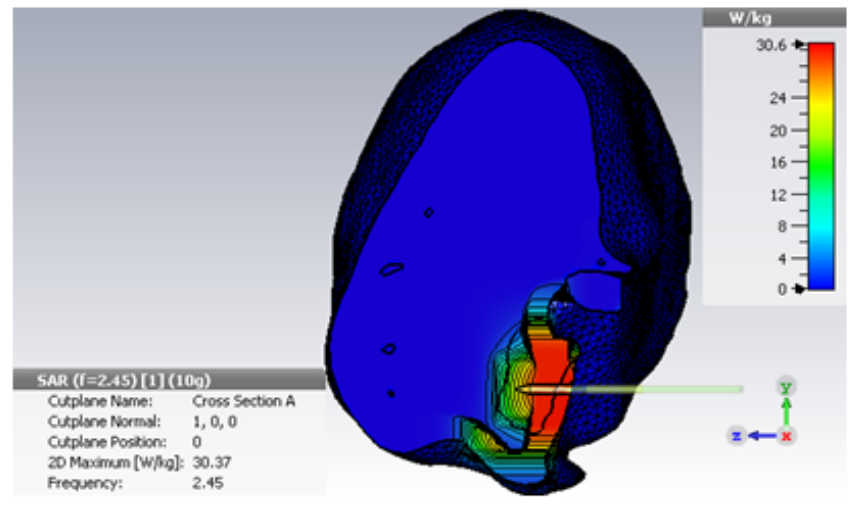

(b)

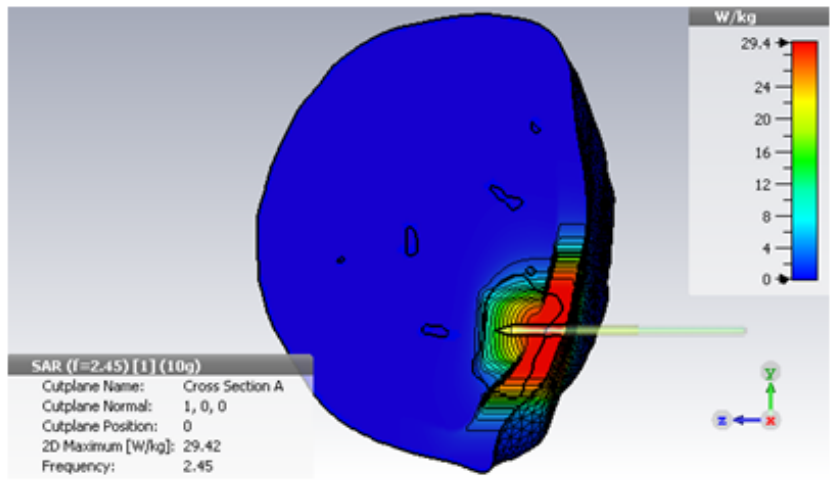

(d)

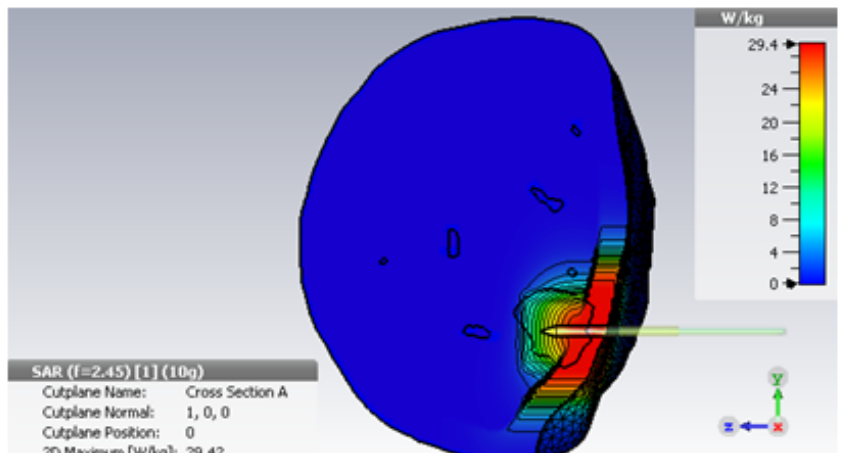

(e)

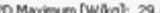

Frequency: $\quad 2.45$

(f)

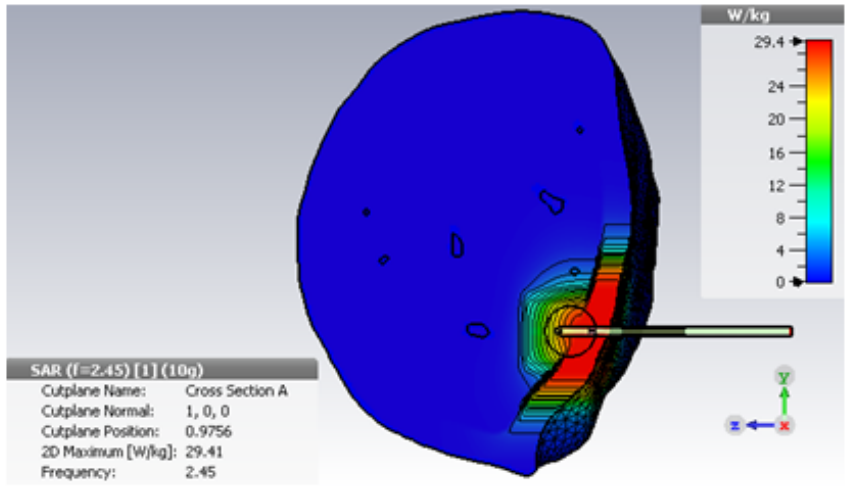

Figure 2

A plot of SAR in the simulation models: (a) SAR in model A, (b) SAR in model B, (c) SAR in model C, (d) SAR in model $D,(e)$ SAR in model $E$, (f) SAR in model $F$. 

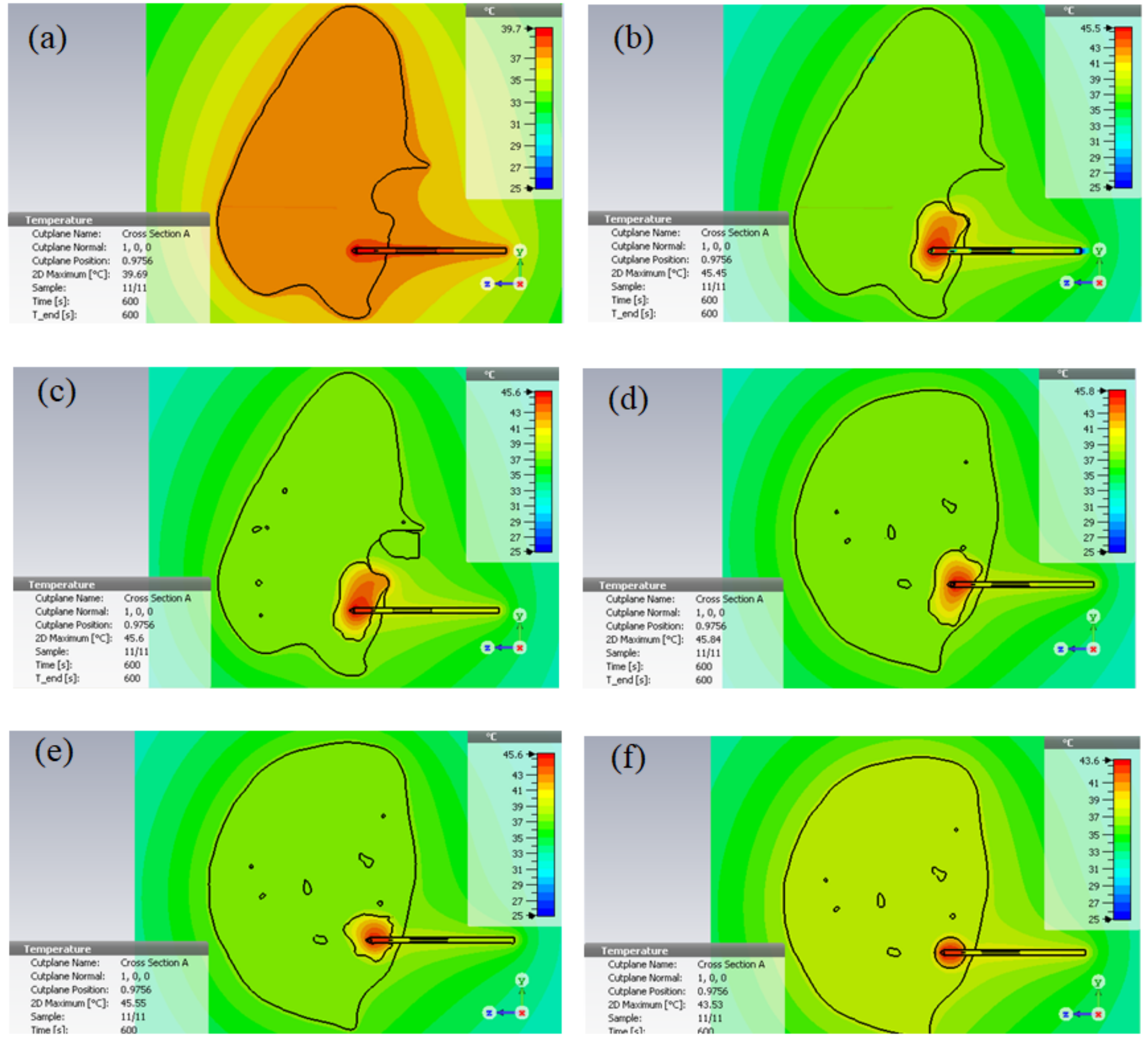

\section{Figure 3}

Cross-section for temperature distribution in simulation models (a) Model A. (b) Model B. (c) Model C. (d) Model D. (e) Model E. (f) Model F 


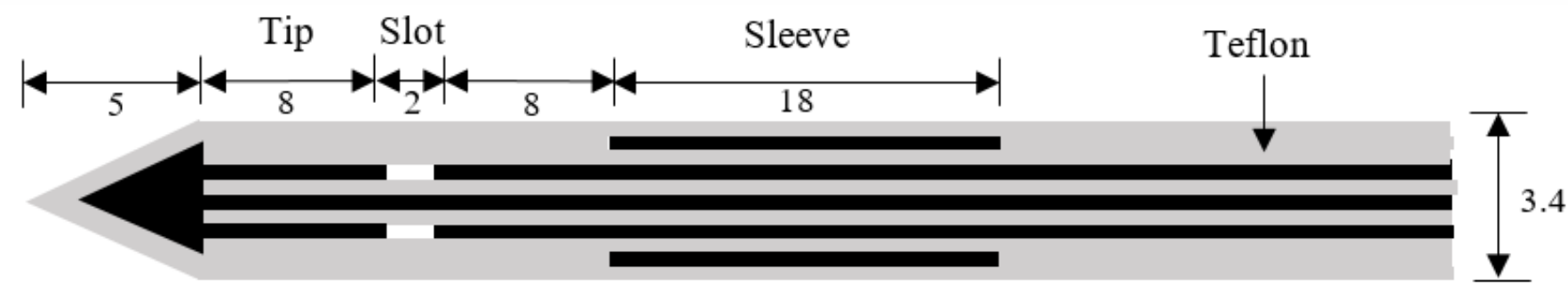

(a)

(b)

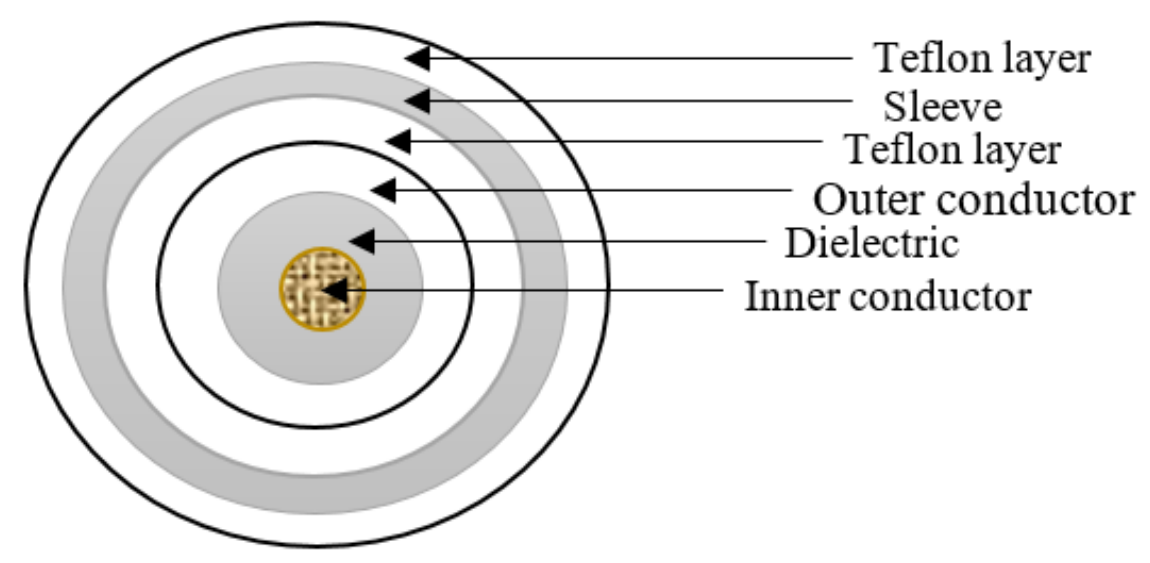

Figure 4

Floating sleeve antenna; (a) Schematic diagram of the floating sleeve antenna; (b) Cross section of the antenna at sleeve 

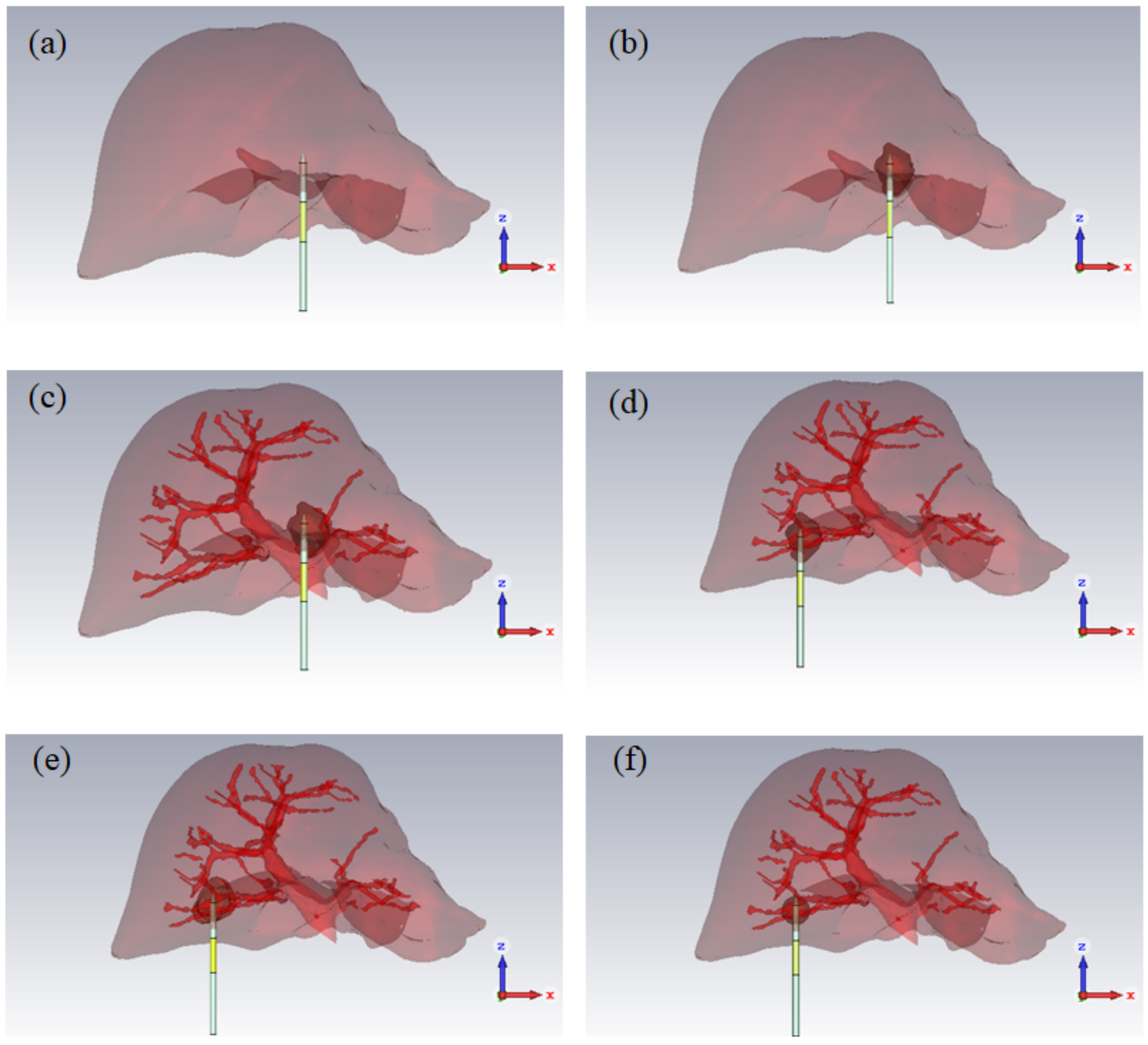

\section{Figure 5}

Simulation models. (a) Model A (no tumor and blood vessels) (b) Model B (with tumor and without blood vessels). (c) Model C (Complete model with $2 \times 3 \mathrm{~cm}$ tumor). (d) Model D $(2 \times 3 \mathrm{~cm}$ tumor at different locations). (e) Model E (smaller tumor about $1.5 \times 1.5 \mathrm{~cm}$ ). (f) Model F $(1.5 \times 1.5 \mathrm{~cm}$ spherical tumor). 